\title{
Extended Use of Extracorporeal Membrane Oxygenation for Acute Respiratory Distress Syndrome: A Retrospective Multicenter Study
}

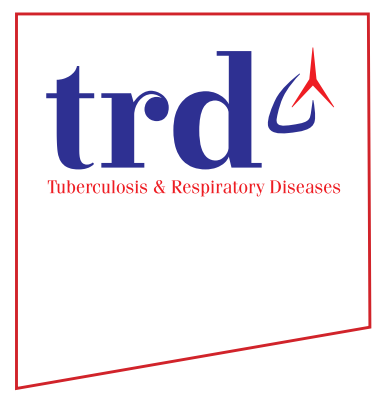

\author{
Won-Young Kim, M.D., Ph.D. ${ }^{1 *}{ }^{\mathbb{D}}$, SeungYong Park, M.D., Ph.D. ${ }^{2 *}{ }^{(\mathbb{D}}$, Hwa Jung Kim, M.D., Ph.D. ${ }^{3}$, \\ Moon Seong Baek, M.D. ${ }^{4}$, Chi Ryang Chung, M.D., Ph.D. , So Hee Park, M.D. ${ }^{6}$, Byung Ju Kang, \\ M.D. ${ }^{7}$, Jin Young Oh, M.D., Ph.D. ${ }^{8}$, Woo Hyun Cho, M.D., Ph.D. ${ }^{9}$, Yun Su Sim, M.D., Ph.D. ${ }^{10}$, \\ Young-Jae Cho, M.D., Ph.D. ${ }^{11}$, Sunghoon Park, M.D., Ph.D. ${ }^{12}$, Jung-Hyun Kim, M.D., Ph.D. ${ }^{13}$ \\ and Sang-Bum Hong, M.D., Ph.D. ${ }^{14}$ (i)
}

*Author affiliations appear at the end of this article.

Background: Beyond its current function as a rescue therapy in acute respiratory distress syndrome (ARDS), extracorporeal membrane oxygenation (ECMO) may be applied in ARDS patients with less severe hypoxemia to facilitate lung protective ventilation. The purpose of this study was to evaluate the efficacy of extended ECMO use in ARDS patients. Methods: This study reviewed 223 adult patients who had been admitted to the intensive care units of 11 hospitals in Korea and subsequently treated using ECMO. Among them, the 62 who required ECMO for ARDS were analyzed. The patients were divided into two groups according to pre-ECMO arterial blood gas: an extended group ( $\mathrm{n}=14)$ and a conventional group $(\mathrm{n}=48)$.

Results: Baseline characteristics were not different between the groups. The median arterial carbon dioxide tension/ fraction of inspired oxygen $\left(\mathrm{FiO}_{2}\right)$ ratio was higher $(97$ vs. $61, \mathrm{p}<0.001)$ while the median $\mathrm{FiO}_{2}$ was lower $(0.8$ vs. 1.0 , $\mathrm{p}<0.001)$ in the extended compared to the conventional group. The 60 -day mortality was $21 \%$ in the extended group and $54 \%$ in the conventional group ( $\mathrm{p}=0.03$ ). Multivariate analysis indicated that the extended use of ECMO was independently associated with reduced 60-day mortality (odds ratio, 0.10; 95\% confidence interval, 0.02-0.64; $\mathrm{p}=0.02$ ). Lower median peak inspiratory pressure and median dynamic driving pressure were observed in the extended group 24 hours after ECMO support.

Conclusion: Extended indications of ECMO implementation coupled with protective ventilator settings may improve the clinical outcome of patients with ARDS.

Keywords: Extracorporeal Membrane Oxygenation; Respiratory Distress Syndrome, Adult; Respiration, Artificial; Retrospective Studies; Multicenter Studies as Topic

Address for correspondence: Sang-Bum Hong, M.D., Ph.D.

Department of Pulmonary and Critical Care Medicine, Asan Medical Center, University of Ulsan College of Medicine, 88 Olympic-ro 43-gil, Songpa-gu, Seoul 05505, Korea

Phone: 82-2-3010-3893, Fax: 82-2-2045-4039, E-mail: sbhong@amc.seoul.kr

*Won-Young Kim and SeungYong Park contributed equally to this work.

Received: Jul. 24, 2018, Revised: Sep. 20, 2018, Accepted: Oct. 25, 2018, Published online: Feb. 28, 2019

@(c) it is identical to the Creative Commons Attribution Non-Commercial License (http://creativecommons.org/licenses/by-nc/4.0/) 


\section{Introduction}

Acute respiratory distress syndrome (ARDS) is characterized by lung injury caused by either direct or indirect insults and leads to severe respiratory failure that is refractory to conventional oxygen therapy ${ }^{1,2}$. Hospital mortality in patients with severe ARDS ranges from $45 \%$ to $60 \%^{2-4}$. Mechanical ventilation is the mainstay of ARDS therapy. However, overdistention and cyclic alveolar recruitment and de-recruitment during ventilation may further damage lungs and increase inflammatory mediators, eventually resulting in multiple organ failure and death ${ }^{5}$. Lung protective ventilation strategies using low tidal volume and higher levels of positive end-expiratory pressure (PEEP) are widely accepted approaches ${ }^{6,7}$, although rescue therapies may still be required in refractory cases.

Extracorporeal membrane oxygenation (ECMO) can provide adequate blood carbon dioxide removal and oxygenation, allowing a reduction in mechanical ventilation and minimization of ventilator-induced lung injury (VILI). Several clinical trials in ARDS have shown positive results of venovenous-ECMO ${ }^{3,8,9}$. Although there are no absolute criteria for ECMO initiation in ARDS, suggested indications include severe hypoxemia (arterial carbon dioxide tension $\left[\mathrm{PaO}_{2}\right] /$ fraction of inspired oxygen $\left[\mathrm{FiO}_{2}\right]$ ratio $<80$ on $\mathrm{FiO}_{2}>0.9$ ), uncompensated hypercapnia with acidemia, or excessively elevated end-inspiratory plateau pressures despite standard ventilator management $t^{10}$. Venovenous-ECMO may be applied in ARDS patients with less severe hypoxemia in whom it might allow "lung rest" by lowering airway pressures and tidal volume rather than improving oxygenation, considering that there is a linear relationship between mortality and plateau pressure, even at less than $30 \mathrm{~cm} \mathrm{H}_{2} \mathrm{O}^{11}$. Moreover, lung hyperinflation occurs in approximately $30 \%$ of ARDS patients ventilated using the protective ARDS Network strategy ${ }^{12}$.

To date, there are limited data on the impact of initiation of ECMO in patients with less severe forms of ARDS. Accordingly, the aim of this study was to compare the clinical characteristics of patients who underwent ECMO for ARDS with less severe hypoxemia (namely "extended indications") versus conventional indications.

\section{Materials and Methods}

\section{Study design and patient selection}

This study was a retrospective analysis of a prospective multicenter cohort. The cohort was composed of critically ill adult patients who were at least 18 years old, received ECMO therapy, and were admitted to one of the intensive care units (ICUs) of the 11 participating tertiary or referral hospitals of Korea from January 2014 to December 2015. From this cohort, we included in our analysis patients who required ECMO sup- port for ARDS. The exclusion criteria were as follows: received lung transplantation (either bridge to transplant or destination therapy), cardiopulmonary resuscitation before ECMO, ECMO transferred from other hospital, venoarterial-ECMO, acute respiratory diagnosis other than ARDS, and incomplete data for analysis. According to the pre-ECMO arterial blood gas, patients were divided into extended $\left(\mathrm{PaO}_{2} / \mathrm{FiO}_{2}\right.$ ratio $\geq 80$ without uncompensated respiratory acidosis) and conventional $\left(\mathrm{PaO}_{2} / \mathrm{FiO}_{2}\right.$ ratio $<80$ on $\mathrm{FiO}_{2}>0.9$ and/or arterial carbon dioxide tension $\left[\mathrm{PaCO}_{2}\right] \geq 80 \mathrm{~mm} \mathrm{Hg}$ with $\mathrm{pH}<7.15$ ) groups. The $\mathrm{PaO}_{2} / \mathrm{FiO}_{2}$ cutoff of 80 was selected based on recently proposed criteria for initiating ECMO in ARDS patients ${ }^{10}$. The primary study outcome was 60-day mortality. Secondary outcomes included ECMO duration, ECMO weaning failure rate, mechanical ventilation weaning success rate, mechanical ventilation-free days at day 60, and 30- and 90-day mortality. We also analyzed factors associated with 60-day mortality, including extended ECMO use. The local institutional review board or independent ethics committee of each hospital approved the study protocol (Institutional Review Board of Asan Medical Center, No. 2016-0269). Written informed consent was waived due to the observational nature of the study, and the patient records were anonymized and de-identified prior to analysis.

\section{Data collection and definitions}

Baseline demographic and clinical characteristics were collected and included age, sex, body mass index, immune status, etiologies of ARDS, dates of hospital and ICU admission, date of initiation of mechanical ventilation and ECMO, and treatment prior to ECMO. Acute Physiology and Chronic Health Evaluation (APACHE) $\mathrm{II}^{13}$ and Sequential Organ Failure Assessment (SOFA) ${ }^{14}$ scores were also collected at the time of ICU admission and ECMO initiation, respectively. The severity of ARDS before ECMO initiation was assessed by the PRedicting dEath for SEvere ARDS on VV-ECMO (PRESERVE) score ${ }^{15}$ and the Respiratory ECMO Survival Prediction (RESP) score ${ }^{16}$ as previously described. The pre-ECMO variables included rescue therapies (neuromuscular blocker, inhaled nitric oxide, or prone positioning), ventilator settings, and arterial blood gas. Ventilator settings included PEEP, peak inspiratory pressure, dynamic driving pressure (the difference between peak inspiratory pressure and PEEP $)^{17}$, tidal volume, respiratory rate, and $\mathrm{FiO}_{2}$, which were determined at baseline (before ECMO application) and at 4 hours and 24 hours thereafter. ARDS was diagnosed by consensus definition ${ }^{2}$. An immunocompromised status was diagnosed if there was an underlying disease that affected the immune system (chronic liver disease, chronic kidney disease, human immunodeficiency virus infection, or malignancy) or if immunosuppressive therapy was being administered at the time of ECMO initiation. Steroid use was defined as corticosteroid adminis- 
tration within 14 days of ECMO initiation.

\section{Statistical analysis}

Continuous variables are presented as median and interquartile range or as mean \pm standard deviation, whereas categorical variables are presented as percentages. Continuous variables were compared using a Mann-Whitney U test or Student's t test. Categorical variables were compared using a chi-square or Fisher exact test. Binary logistic regression was used to identify factors predicting 60-day mortality. Variables with p-values $<0.20$ in the univariate analysis were included in the multivariate analysis by using stepwise backward selection procedures. Highly correlated variables were identified to prevent multicollinearity. Model discrimination was assessed with the area under the receiver operating characteristic curve, and model calibration was assessed with the HosmerLemeshow test. A Cox proportional hazards regression model with stepwise backward selection procedures was also applied. The Kaplan-Meier curve was rendered to compare 60day survival among the groups. All tests of significance were two-tailed, and p-values of $<0.05$ were considered significant. All analyses were performed using SPSS version 18.0 for Windows (SPSS Inc., Chicago, IL, USA).

\section{Results}

There were 223 patients in the initial cohort; 161 were not included for the following reasons: met specific exclusion criteria $(\mathrm{n}=90)$; ECMO provided for an acute respiratory diag- nosis other than ARDS ( $\mathrm{n}=68$ ); and pre-ECMO arterial blood gas unavailable for analysis $(\mathrm{n}=3)$. Our study consisted of 62 ARDS patients who received ECMO as a rescue therapy. There were 14 patients (23\%) in the extended group and 48 (77\%) in the conventional group (Figure 1).

The baseline characteristics of the study patients are shown in Table 1 . The percentage of male patients was significantly higher in the extended than in the conventional group, but there were no differences in age or body mass index. The proportion of immunocompromised patients was also similar between the two groups. In both groups, the main etiology of ARDS was bacterial pneumonia, followed by viral pneumonia. There were no differences between the groups in baseline APACHE II and SOFA scores, treatment prior to ECMO, and pre-ECMO rescue therapies. There was no difference between the groups in time from intubation to ECMO cannulation. The median PRESERVE and RESP scores were similar between the two groups ( 4 [3-6] vs. $5[4-6], \mathrm{p}=0.50$; and $3[0-5]$ vs. 2 [1-4], $\mathrm{p}=0.33$, respectively). Compared with the conventional group, the extended group had a significantly higher median $\mathrm{PaO}_{2} / \mathrm{FiO}_{2}$ ratio (97 [88-112] vs. 61 [53-70], $\left.\mathrm{p}<0.001\right)$ and lower median $\mathrm{FiO}_{2}(0.8[0.7-1.0]$ vs. 1.0 [1.0-1.0], $\mathrm{p}<0.001)$. Other ventilator settings before ECMO support were not significantly different between the two groups.

Clinical outcomes of the study patients are shown in Table 2 . The primary outcome, 60 -day mortality, was observed in three of the 14 patients (21\%) in the extended group and 26 of the 48 patients (54\%) in the conventional group $(\mathrm{p}=0.03)$. In addition, 90-day mortality was significantly lower in the extended group $(3 / 14,21 \%)$ than in the conventional group $(27 / 48,56 \%)(\mathrm{p}=0.02)$, although the 30-day mortality rate

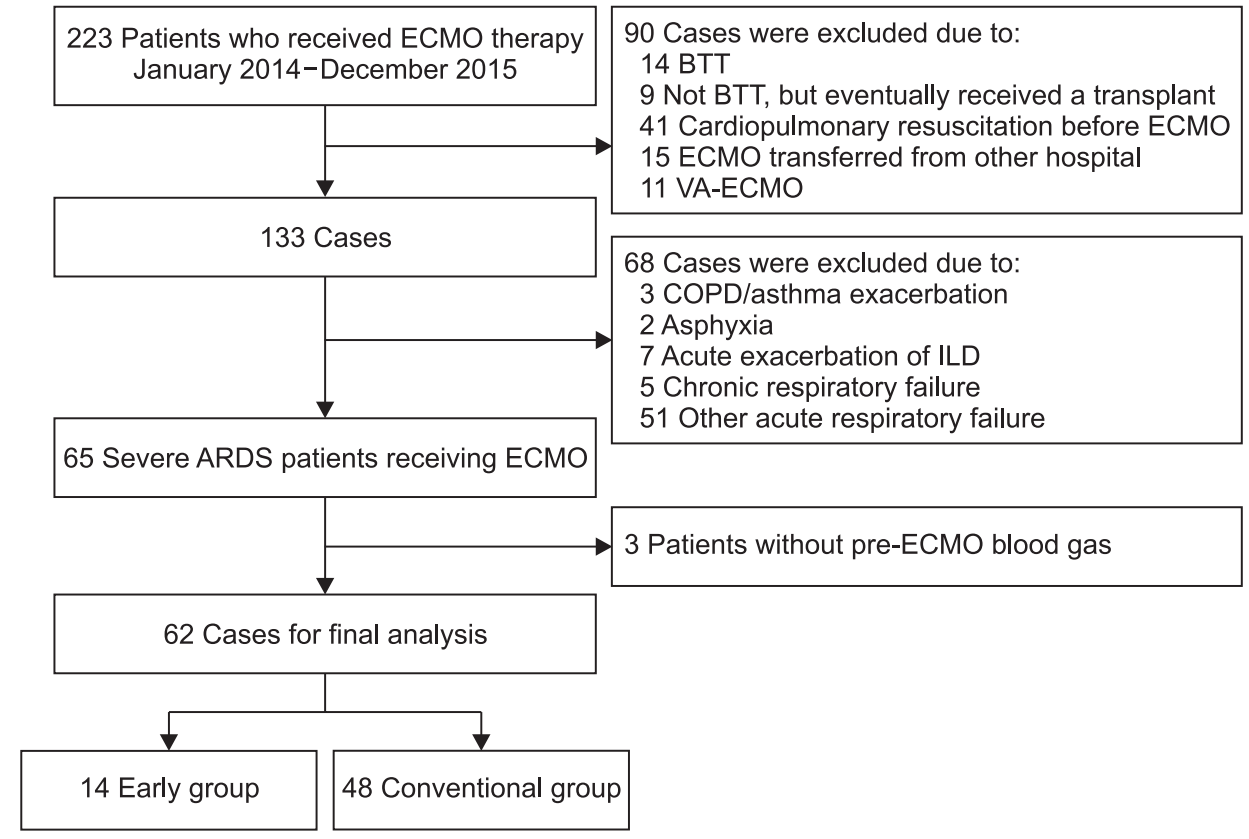

Figure 1. Illustration of a study flow diagram. ECMO: extracorporeal membrane oxygenation; BTT: bridge to transplant; VA: venoarterial; COPD: chronic obstructive pulmonary disease; ILD: interstitial lung disease; ARDS: acute respiratory distress syndrome. 
Table 1. Baseline characteristics of the study patients

\begin{tabular}{|c|c|c|c|}
\hline Variable & Extended group $(n=14)$ & Conventional group $(n=48)$ & p-value \\
\hline Age, yr & $50(35-61)$ & $59(46-65)$ & 0.21 \\
\hline Male sex & $14(100)$ & $31(65)$ & 0.007 \\
\hline Body mass index, $\mathrm{kg} / \mathrm{m}^{2}$ & $24.9(21.3-26.9)$ & $23.3(20.6-25.0)$ & 0.19 \\
\hline Immunocompromised & $2(14)$ & $9(19)$ & $>0.99$ \\
\hline ARDS etiology & & & 0.57 \\
\hline Viral pneumonia & $4(29)$ & $13(27)$ & \\
\hline Bacterial pneumonia & $8(57)$ & $32(67)$ & \\
\hline Trauma/burn & $2(14)$ & $3(6)$ & \\
\hline APACHE II score at ICU admission & $20(12-25)$ & $19(14-26)$ & 0.96 \\
\hline SOFA score at ECMO initiation & $13(11-16)$ & $11(7-14)$ & 0.07 \\
\hline Pre-ECMO renal replacement therapy & $3(21)$ & $10(21)$ & $>0.99$ \\
\hline Pre-ECMO steroids & $2(14)$ & $6(13)$ & $>0.99$ \\
\hline Pre-ECMO bicarbonate infusion & $2(14)$ & $8(17)$ & $>0.99$ \\
\hline \multicolumn{4}{|l|}{ Pre-ECMO rescue therapy } \\
\hline Neuromuscular blocker & $10(71)$ & $35(73)$ & $>0.99$ \\
\hline Inhaled nitric oxide & $6(43)$ & $12(25)$ & 0.32 \\
\hline Prone positioning & $6(43)$ & $22(46)$ & 0.84 \\
\hline Time between MV-ECMO, day & $1.5(1.0-5.0)$ & $1.0(0-3.5)$ & 0.43 \\
\hline PRESERVE score & $4(3-6)$ & $5(4-6)$ & 0.50 \\
\hline RESP score & $3(0-5)$ & $2(1-4)$ & 0.33 \\
\hline \multicolumn{4}{|l|}{ Pre-ECMO ventilator settings } \\
\hline Positive end-expiratory pressure, $\mathrm{cm} \mathrm{H}_{2} \mathrm{O}$ & $10(10-12)$ & $10(8-12)$ & 0.60 \\
\hline Peak inspiratory pressure, $\mathrm{cm} \mathrm{H}_{2} \mathrm{O}$ & $28(27-30)$ & $28(23-30)$ & 0.67 \\
\hline Dynamic driving pressure, $\mathrm{cm} \mathrm{H}_{2} \mathrm{O}$ & $17(15-20)$ & $16(14-20)$ & 0.58 \\
\hline Tidal volume, $\mathrm{mL}$ & $436(350-512)$ & $390(300-600)$ & 0.83 \\
\hline Respiratory rate, breaths/min & $23(20-28)$ & $22(16-27)$ & 0.37 \\
\hline $\mathrm{FiO}_{2}$ & $0.8(0.7-1.0)$ & $1.0(1.0-1.0)$ & $<0.001$ \\
\hline \multicolumn{4}{|l|}{ Pre-ECMO arterial blood gas } \\
\hline $\mathrm{pH}$ & $7.29(7.23-7.40)$ & $7.26(7.17-7.33)$ & 0.15 \\
\hline $\mathrm{PaCO}_{2}, \mathrm{~mm} \mathrm{Hg}$ & $47(40-50)$ & $52(38-66)$ & 0.17 \\
\hline $\mathrm{PaO}_{2}, \mathrm{~mm} \mathrm{Hg}$ & $84(67-94)$ & $60(53-69)$ & $<0.001$ \\
\hline $\mathrm{PaO}_{2} / \mathrm{FiO}_{2}$ & $97(88-112)$ & $61(53-70)$ & $<0.001$ \\
\hline Bicarbonate, $\mathrm{mEq} / \mathrm{L}$ & $22.1(18.7-25.0)$ & $22.0(18.1-26.7)$ & 0.87 \\
\hline
\end{tabular}

Values are presented as median (interquartile range) or number (\%).

ARDS: acute respiratory distress syndrome; APACHE: Acute Physiology and Chronic Health Evaluation; ICU: intensive care unit; SOFA: Sequential Organ Failure Assessment; ECMO: extracorporeal membrane oxygenation; MV: mechanical ventilation; PRESERVE: PRedicting dEath for SEvere ARDS on VV-ECMO; RESP: Respiratory ECMO Survival Prediction; $\mathrm{FiO}_{2}$ : fraction of inspired oxygen; PaCO ${ }_{2}$ arterial carbon dioxide tension; $\mathrm{PaO}_{2}$ : arterial oxygen tension.

was comparable between the groups. The median duration of ECMO was $8.0(4.0-14.0)$ days in the extended group and $9.0(6.0-23.5)$ days in the conventional group $(\mathrm{p}=0.37)$. There were no differences between the groups in the ECMO wean- ing failure rate and tracheostomy rate. Both the mechanical ventilation weaning success rate and mechanical ventilationfree days at day 60 tended to be more favorable in the extended than in the conventional group, although the results were 
not statistically significant. The Kaplan-Meier survival curves of the study patients are shown in Figure 2.

The results of univariate and multivariate analyses of risk factors predicting 60-day mortality are shown in Table 3. Multivariate analysis indicated that inhaled nitric oxide as preECMO rescue therapy was significantly associated with mortality. Conversely, extended ECMO use was a protective factor (odds ratio, 0.10; 95\% confidence interval, 0.02-0.64; $\mathrm{p}=0.02$ ). This model had acceptable discrimination (area under the receiver operating characteristic curve $=0.72$ ) and calibration (Hosmer and Lemeshow chi-square $=1.10$; $\mathrm{p}=0.58$ ). Consistently, inhaled nitric oxide and extended ECMO use were independently associated with "time to 60-day mortality" using Cox proportional hazards modeling (Table 4).

The changes in ventilator settings between the study groups during the 24-hour study period are shown in Figure 3 and Supplementary Table S1. After ECMO support, tidal volume, respiratory rate, and $\mathrm{FiO}_{2}$ were decreased, but there were no significant differences between the extended and conventional groups until 24 hours. Both peak inspiratory pressure and dynamic driving pressure were decreased after ECMO initiation. The extended group had significantly lower median peak inspiratory pressure after 24-hour ECMO support (20 [18-20] $\mathrm{cm}_{2} \mathrm{O}$ vs. 22 [20-24] $\mathrm{cm} \mathrm{H}_{2} \mathrm{O}, \mathrm{p}=0.006$ ). The extended group also tended to have lower median dynamic driving pressure after 24-hour ECMO support (10 [10-12] $\mathrm{cm} \mathrm{H}_{2} \mathrm{O}$ vs. 12 [1015] $\left.\mathrm{cm} \mathrm{H}_{2} \mathrm{O}, \mathrm{p}=0.13\right)$.

\section{Discussion}

The present study revealed a lower mortality rate in patients who received ECMO for ARDS with an extended indication, and extended ECMO use itself was positively associated with survival. The 54\% 60-day mortality in the conventional group (where the median PRESERVE and RESP scores at ECMO initiation were 5 and 2, respectively) is comparable with the $43 \%-46 \%$ mortality rates reported in previous studies of similar ECMO-treated ARDS patients ${ }^{15,16}$. However, despite comparable severity at ECMO initiation, mortality was lower than expected in the extended group. In the extended group, lower median peak inspiratory pressure and median dynamic driving pressure were observed within 24 hours after ECMO initiation. These findings suggest that extended indications of ECMO implementation than conventional indications accompanied by an additional "lung rest" may improve the clinical outcome. To our knowledge, this is one of the few studies to evaluate the role of extended ECMO use in patients with ARDS.

Lung protective ventilator settings that keep tidal volume and plateau pressures within narrow limits should be used in ARDS patients to improve outcomes and prevent the development of VILI ${ }^{18}$. However, when there is dramatic hypoxemia and/or profound acidosis with a high degree of hypercapnia,

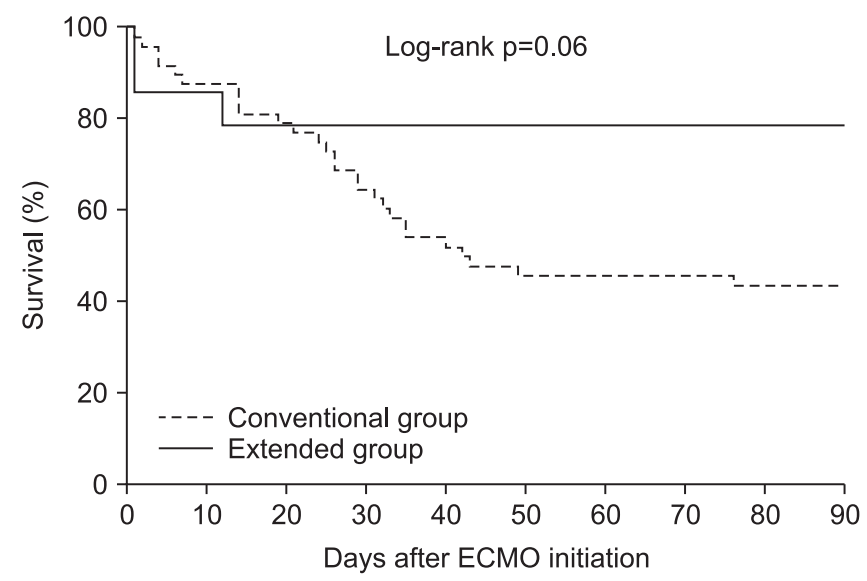

Figure 2. Kaplan-Meier survival curves of the patients under study. ECMO: extracorporeal membrane oxygenation.

Table 2. Clinical outcomes of the study patients

\begin{tabular}{|lccc|}
\hline \multicolumn{1}{|c}{ Variable } & Extended group $(\mathbf{n = 1 4 )}$ & Conventional group $(\mathbf{n}=\mathbf{4 8})$ & $\mathbf{p}$-value \\
\hline ECMO duration, day & $8.0(4.0-14.0)$ & $9.0(6.0-23.5)$ & 0.37 \\
\hline ECMO weaning failure & $4(29)$ & $18(38)$ & 0.75 \\
\hline Tracheostomy & $6(43)$ & $26(55)$ & 0.41 \\
\hline MV weaning success & $8(57)$ & $17(35)$ & 0.15 \\
\hline MV-free days at day 60 & $23.3 \pm 24.7$ & $16.1 \pm 23.4$ & 0.35 \\
\hline Mortality & & & 0.52 \\
\hline 30-Day & $3(21)$ & $17(35)$ & 0.03 \\
\hline 60-Day & $3(21)$ & $26(54)$ & 0.02 \\
\hline 90-Day & $3(21)$ & $27(56)$ & \\
\hline
\end{tabular}

Values are presented as median (interquartile range), number (\%), or mean \pm standard deviation.

ECMO: extracorporeal membrane oxygenation; MV: mechanical ventilation. 
Table 3. Univariate and multivariate analysis of factors associated with 60-day mortality

\begin{tabular}{|c|c|c|c|c|}
\hline Variable & Unadjusted OR (95\% CI) & p-value & Adjusted OR* (95\% CI) & p-value \\
\hline Age & $1.03(0.99-1.07)$ & 0.16 & - & - \\
\hline Male sex & $0.51(0.17-1.59)$ & 0.25 & - & - \\
\hline Bacterial pneumonia & $1.93(0.67-5.63)$ & 0.23 & - & - \\
\hline Trauma/burn & $0.26(0.03-2.46)$ & 0.24 & - & - \\
\hline APACHE II score at ICU admission & $1.04(0.98-1.11)$ & 0.22 & - & - \\
\hline Pre-ECMO renal replacement therapy & $2.13(0.61-7.46)$ & 0.24 & - & - \\
\hline Pre-ECMO prone positioning & $0.58(0.21-1.59)$ & 0.29 & - & - \\
\hline Pre-ECMO inhaled nitric oxide & $4.55(1.37-15.11)$ & 0.01 & $7.96(1.58-40.06)$ & 0.01 \\
\hline Pre-ECMO dynamic driving pressure & $1.11(0.999-1.23)$ & 0.051 & - & - \\
\hline Pre-ECMO respiratory rate & $1.04(0.97-1.12)$ & 0.29 & - & - \\
\hline Pre-ECMO $\mathrm{PaO}_{2} / \mathrm{FiO}_{2}$ & $1.01(0.99-1.02)$ & 0.31 & - & - \\
\hline Extended ECMO use & $0.23(0.06-0.93)$ & 0.04 & $0.10(0.02-0.64)$ & 0.02 \\
\hline
\end{tabular}

*Variables with p-values of $<0.20$ in the univariate analysis were included in the multivariate analysis by using stepwise backward selection procedures.

OR: odds ratio; CI: confidence interval; APACHE: Acute Physiology and Chronic Health Evaluation; ICU: intensive care unit; ECMO: extracorporeal membrane oxygenation; $\mathrm{PaO}_{2}$ : arterial oxygen tension; $\mathrm{FiO}_{2}$ : fraction of inspired oxygen.

Table 4. Cox proportional hazards regression model with 60-day mortality as outcome

\begin{tabular}{|c|c|c|c|c|}
\hline Variable & Unadjusted HR (95\% CI) & p-value & Adjusted HR* (95\% CI) & p-value \\
\hline Male sex & $0.56(0.26-1.21)$ & 0.14 & - & - \\
\hline APACHE II score at ICU admission & $1.03(0.99-1.07)$ & 0.20 & - & - \\
\hline Pre-ECMO renal replacement therapy & $1.84(0.81-4.16)$ & 0.14 & - & - \\
\hline Pre-ECMO prone positioning & $0.62(0.29-1.31)$ & 0.21 & - & - \\
\hline Pre-ECMO inhaled nitric oxide & $3.24(1.55-6.77)$ & 0.002 & $4.19(1.87-9.36)$ & $<0.001$ \\
\hline Pre-ECMO bicarbonate infusion & $1.72(0.70-4.23)$ & 0.24 & - & - \\
\hline Pre-ECMO dynamic driving pressure & $1.07(1.003-1.13)$ & 0.04 & - & - \\
\hline Pre-ECMO respiratory rate & $1.03(0.97-1.09)$ & 0.28 & - & - \\
\hline Pre-ECMO $\mathrm{PaO}_{2} / \mathrm{FiO}_{2}$ & $1.01(0.999-1.02)$ & 0.09 & $1.01(1.01-1.02)$ & 0.001 \\
\hline Extended ECMO use & $0.36(0.11-1.18)$ & 0.09 & $0.19(0.06-0.66)$ & 0.009 \\
\hline
\end{tabular}

*Variables with p-values of $<0.20$ were included in the multivariate analysis using stepwise backward selection procedures.

HR: hazard ratio; CI: confidence interval; APACHE: Acute Physiology and Chronic Health Evaluation; ICU: intensive care unit; ECMO: extracorporeal membrane oxygenation; $\mathrm{PaO}_{2}$ : arterial oxygen tension; $\mathrm{FiO}_{2}$ : fraction of inspired oxygen.

these "protective" mechanical ventilation strategies may not be possible. In addition, even if the above-mentioned variables are kept within the defined limits, the patient might not be ventilated in a lung protective manner ${ }^{11,12}$. Rescue therapies such as ECMO may be used timely or even immediately to resolve potentially deleterious conditions, although defined thresholds of mechanical ventilation that characterize the status under which the therapy is to be applied are required. However, a clear cutoff that defines severe or life-threatening hypoxemia is still an ongoing matter of debate ${ }^{19}$, and evidence supporting indications or contraindications to ECMO initia- tion in ARDS is scarce. A recent international multicenter randomized ECMO to Rescue Lung Injury in Severe ARDS (EOLIA) trial tested the efficacy of early venovenous-ECMO in patients with severe ARDS with conventional mechanical ventilation with prone positioning ${ }^{20}$. The analysis of the primary end point (60-day mortality) showed no significant benefit of early ECMO, although the $28 \%$ rate of crossover to ECMO among patients with refractory hypoxemia in the conventional group ( $43 \%$ of them survived) may have diluted the potential effect of ECMO. Meanwhile, patients who were enrolled in this trial were very hypoxemic $\left(\mathrm{PaO}_{2} / \mathrm{FiO}_{2}\right.$ ratio $\left.<80\right)$ 

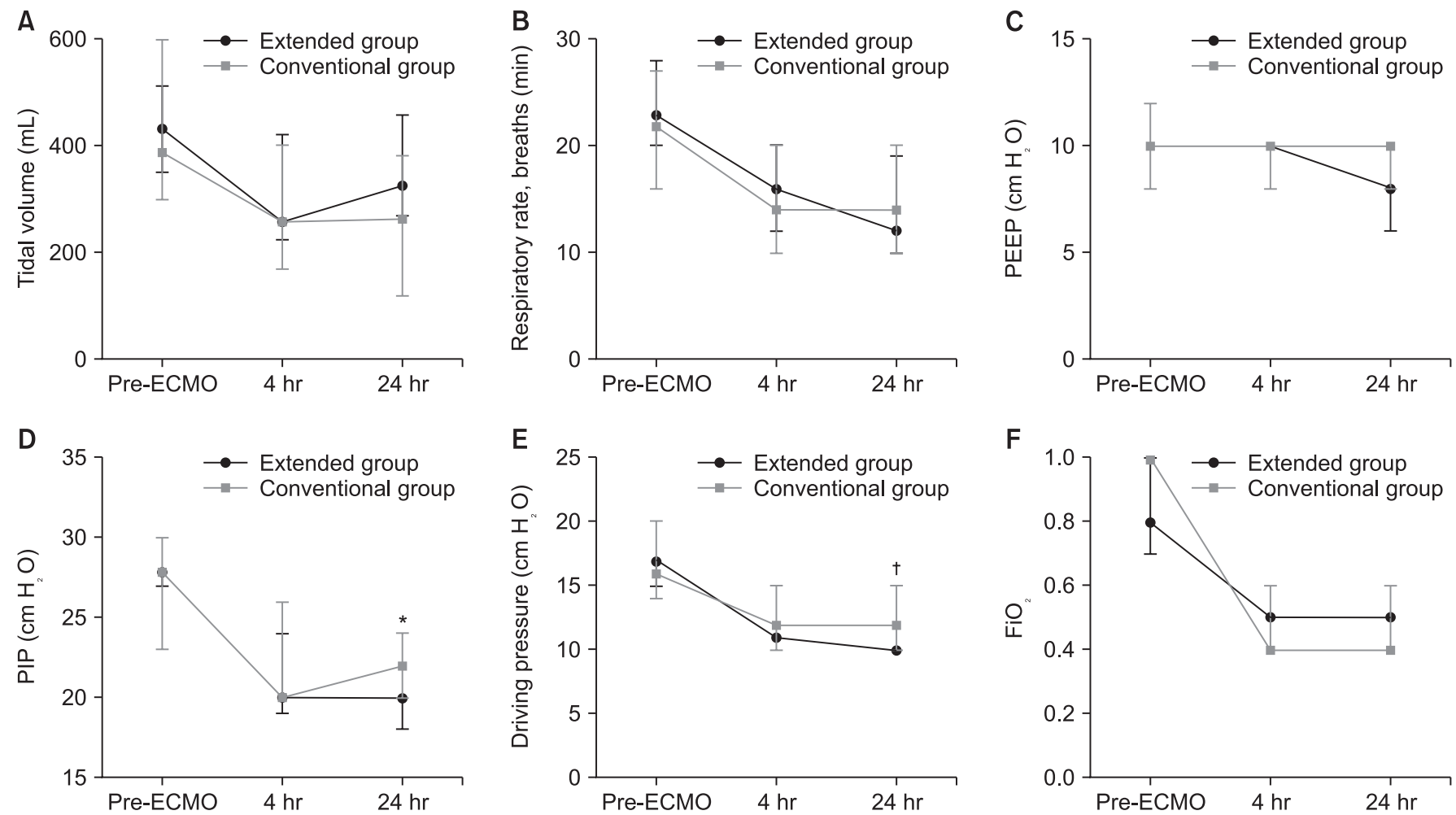

Figure 3. Serial changes in tidal volume (A), respiratory rate (B), positive end-expiratory pressure (PEEP) (C), peak inspiratory pressure (PIP) (D), dynamic driving pressure (E), and fraction of inspired oxygen $\left(\mathrm{FiO}_{2}\right)(\mathrm{F})$ in the extended group (dark line) and the conventional group (gray line) during the 24 -hour study period. Data is presented as a median value (interquartile range). ${ }^{*} \mathrm{p}<0.05$. ${ }^{\dagger} \mathrm{p}=0.13$. ECMO: extracorporeal membrane oxygenation.

and the trial did not evaluate patients with less severe forms of ARDS.

The use of ECMO in ARDS patients with less severe hypoxemia may be beneficial for the following reasons. First, venovenous-ECMO with an "ultraprotective" mechanical ventilation strategy (tidal volume reduction to below $6 \mathrm{ml} / \mathrm{kg}$ of predicted body weight to achieve a plateau pressure less than $25 \mathrm{~cm} \mathrm{H}_{2} \mathrm{O}$ ) may further reduce VILI and mortality in patients mechanically ventilated for $\mathrm{ARDS}^{21,22}$. In addition, venovenous-ECMO may reduce the effect of acute lung injury on right ventricular dysfunction by reducing hypoxic pulmonary vasoconstriction and unloading the right ventricle ${ }^{23}$. Second, modern ECMO devices are simpler, safer, and require less anticoagulation and it is now possible to support patients for weeks ${ }^{24}$. Third, patients with ECMO can be awake, facilitating rehabilitation and decreasing weakness and deconditioning. Several studies indicate that early rehabilitation in ECMO patients may improve survival, reduce mechanical ventilation duration, shorten ICU length of stay, and improve functional recovery ${ }^{25,26}$. Fourth, ECMO might improve long-term qualityof-life by improving blood oxygenation in severely hypoxemic ARDS patients. In fact, ARDS patients treated with $\mathrm{ECMO}^{3,15}$ showed comparable or better health-related quality-of- life scores than patients with less severe ARDS treated with conventional management ${ }^{27}$. Lastly, several studies have identified duration of mechanical ventilation prior to ECMO initiation and low pre-ECMO respiratory system compliance as factors strongly associated with mortality in severe ARDS patients receiving $\mathrm{ECMO}^{15,16,28}$.

Several studies have described the impact of different ventilator settings in ARDS patients undergoing $\mathrm{ECMO}^{17,22,28}$, with lower PEEP levels and higher driving pressure independently associated with mortality. In this study, we observed changes in ventilator settings within 24 hours of ECMO initiation. Thus, the extended group had lower peak inspiratory pressure and dynamic driving pressure after 24-hour ECMO support. We used the difference between the peak inspiratory pressure and PEEP to calculate the "dynamic" driving pressure ${ }^{17}$ because most patients were on pressure-controlled ventilation during the evaluation of ventilator settings. Moreover, our multivariate logistic regression and Cox proportional hazards modeling demonstrated that the extended group was independently associated with 60-day survival. Based on our findings, implementation of ECMO with extended indications accompanied by protective ventilation settings may affect the clinical outcome in ARDS patients. 
This multicenter study had several limitations of note. First, the study was retrospective and underpowered. Its nonrandomized design was prone to selection bias and precluded any inference of causality regarding the association between extended ECMO use and outcome. We also could not adjust for unmeasured confounders, and a matching process between the two groups was not feasible due to a relatively small sample size used for the extended group compared with that of conventional group. In addition, the multiple confounding factors may have affected the clinical outcome, despite the similar baseline characteristics of the study patients in the extended and conventional groups. Second, one could argue that the better outcomes in the extended group could have been related with the better oxygenation status of patients, considering that several studies identified oxygenation criteria as a predictor of mortality in $\mathrm{ARDS}^{2,29}$. However, the multivariate analysis showed no relation between $\mathrm{PaO}_{2} / \mathrm{FiO}_{2}$ ratio and mortality. The Cox regression analysis even showed a positive association between increased $\mathrm{PaO}_{2} / \mathrm{FiO}_{2}$ ratio and mortality, although it is difficult to explain such a phenomenon. Moreover, pre-ECMO ventilator settings in the extended group were comparable to those in the conventional group, and most patients in the extended group had already been managed with other rescue therapies before ECMO initiation. Third, ventilator settings were collected only at baseline, 4 hours, and 24 hours after ECMO application. We do not know if specific ventilator strategies after day 1 would have changed the patient outcomes. Lastly, criteria for assessing ECMO for ARDS, mechanical ventilation on ECMO, and weaning from ECMO were not standardized among centers. In addition, there was a lack of data on some of the treatment modalities (level of sedation, ECMO settings, anticoagulation, transfusion, or rehabilitation) and complications (either directly related to the ECMO circuit or patient-related) because these data were not collected due to the purposes of the initial cohort. It remains possible that the two groups were not similarly treated, and this may have affected the treatment outcome.

In conclusion, our comparison of extended indications of ECMO implementation with conventional indications suggests that extended ECMO use accompanied by protective ventilation strategies may improve the clinical outcome for patients with ARDS.

\section{*Author affiliations}

${ }^{1}$ Division of Pulmonary, Allergy and Critical Care Medicine, Department of Internal Medicine, Pusan National University, School of Medicine, Busan, ${ }^{2}$ Department of Internal Medicine, Chonbuk National University Medical School, Jeonju, ${ }^{3}$ Department of Clinical Epidemiology and Biostatistics, Asan Medical Center, University of Ulsan College of Medicine, Seoul, ${ }^{4}$ Department of Pulmonary, Allergy, and Critical Care Medicine,
Hallym University Dongtan Sacred Heart Hospital, Hwaseong, ${ }^{5}$ Department of Critical Care Medicine, Samsung Medical Center, Sungkyunkwan University School of Medicine, Seoul, ${ }^{6}$ Department of Pulmonary and Critical Care Medicine, Kyung Hee University Hospital at Gangdong, Kyung Hee University School of Medicine, Seoul, ${ }^{7}$ Department of Internal Medicine, Ulsan University Hospital, University of Ulsan College of Medicine, Ulsan, ${ }^{8}$ Division of Pulmonology and Critical Care Medicine, Dongguk University Ilsan Hospital, Dongguk University College of Medicine, Goyang, ${ }^{9}$ Department of Pulmonology and Critical Care Medicine, Pusan National University Yangsan Hospital, Yangsan, ${ }^{10}$ Division of Pulmonary and Critical Care Medicine, Department of Medicine, Hallym University Kangnam Sacred Heart Hospital, Seoul, ${ }^{11}$ Division of Pulmonary and Critical Care Medicine, Department of Internal Medicine, Seoul National University Bundang Hospital, Seoul National University College of Medicine, Seongnam, ${ }^{12}$ Division of Pulmonary and Critical Care Medicine, Department of Medicine, Hallym University Sacred Heart Hospital, Anyang, ${ }^{13}$ Department of Internal Medicine, CHA Bundang Medical Center, CHA University School of Medicine, Seongnam, ${ }^{14}$ Department of Pulmonary and Critical Care Medicine, Asan Medical Center, University of Ulsan College of Medicine, Seoul, Korea

\section{Authors' Contributions}

Conceptualization: Hong SB. Methodology: Kim WY, Park S. Formal analysis: Kim HJ. Data curation: Baek MS. Investigation: Park S, Baek MS, Chung CR, Park SH, Kang BJ, Oh JY, Cho WH, Sim YS, Cho YJ, Park S, Kim JH. Writing - original draft preparation: Kim WY. Writing - review and editing: Park S, Chung CR, Park SH, Kang BJ, Oh JY, Cho WH, Sim YS, Cho YJ, Park S, Kim JH, Hong SB. Approval of final manuscript: all authors.

\section{Conflicts of Interest}

No potential conflict of interest relevant to this article was reported.

\section{Acknowledgments}

This research was supported by a 2015 grant from the Korean Academy of Tuberculosis and Respiratory Diseases. The funders had no role in study design, data collection and analysis, preparation of the manuscript, or decision to publish. 


\section{Supplementary Material}

Supplementary material can be found in the journal homepage (http://www.e-trd.org).

Supplementary Table S1. Changes in ventilator settings between the extended group and the conventional group during the 24-hour study period.

\section{References}

1. Ware LB, Matthay MA. The acute respiratory distress syndrome. N Engl J Med 2000;342:1334-49.

2. ARDS Definition Task Force, Ranieri VM, Rubenfeld GD, Thompson BT, Ferguson ND, Caldwell E, et al. Acute respiratory distress syndrome: the Berlin definition. JAMA 2012; 307:2526-33.

3. Peek GJ, Mugford M, Tiruvoipati R, Wilson A, Allen E, Thalanany MM, et al. Efficacy and economic assessment of conventional ventilatory support versus extracorporeal membrane oxygenation for severe adult respiratory failure (CESAR): a multicentre randomised controlled trial. Lancet 2009;374:1351-63.

4. Villar J, Blanco J, Anon JM, Santos-Bouza A, Blanch L, Ambros A, et al. The ALIEN study: incidence and outcome of acute respiratory distress syndrome in the era of lung protective ventilation. Intensive Care Med 2011;37:1932-41.

5. Slutsky AS, Ranieri VM. Ventilator-induced lung injury. N Engl J Med 2013;369:2126-36.

6. Acute Respiratory Distress Syndrome Network, Brower RG, Matthay MA, Morris A, Schoenfeld D, Thompson BT, et al. Ventilation with lower tidal volumes as compared with traditional tidal volumes for acute lung injury and the acute respiratory distress syndrome. N Engl J Med 2000;342:1301-8.

7. Briel M, Meade M, Mercat A, Brower RG, Talmor D, Walter $\mathrm{SD}$, et al. Higher vs lower positive end-expiratory pressure in patients with acute lung injury and acute respiratory distress syndrome: systematic review and meta-analysis. JAMA 2010;303:865-73.

8. Australia and New Zealand Extracorporeal Membrane Oxygenation (ANZ ECMO) Influenza Investigators, Davies A, Jones D, Bailey M, Beca J, Bellomo R, et al. Extracorporeal membrane oxygenation for 2009 influenza A (H1N1) acute respiratory distress syndrome. JAMA 2009;302:1888-95.

9. Pham T, Combes A, Roze H, Chevret S, Mercat A, Roch A, et al. Extracorporeal membrane oxygenation for pandemic influenza $\mathrm{A}(\mathrm{H} 1 \mathrm{~N} 1)$-induced acute respiratory distress syndrome: a cohort study and propensity-matched analysis. Am J Respir Crit Care Med 2013;187:276-85.

10. Brodie D, Bacchetta M. Extracorporeal membrane oxygenation for ARDS in adults. N Engl J Med 2011;365:1905-14.

11. Hager DN, Krishnan JA, Hayden DL, Brower RG; ARDS Clinical Trials Network. Tidal volume reduction in patients with acute lung injury when plateau pressures are not high. Am J Respir Crit Care Med 2005;172:1241-5.

12. Terragni PP, Rosboch G, Tealdi A, Corno E, Menaldo E, Davini $\mathrm{O}$, et al. Tidal hyperinflation during low tidal volume ventilation in acute respiratory distress syndrome. Am J Respir Crit Care Med 2007;175:160-6.

13. Knaus WA, Draper EA, Wagner DP, Zimmerman JE. APACHE II: a severity of disease classification system. Crit Care Med 1985;13:818-29.

14. Vincent JL, Moreno R, Takala J, Willatts S, De Mendonca A, Bruining H, et al. The SOFA (Sepsis-related Organ Failure Assessment) score to describe organ dysfunction/failure. On behalf of the Working Group on Sepsis-Related Problems of the European Society of Intensive Care Medicine. Intensive Care Med 1996;22:707-10.

15. Schmidt M, Zogheib E, Roze H, Repesse X, Lebreton G, Luyt CE, et al. The PRESERVE mortality risk score and analysis of long-term outcomes after extracorporeal membrane oxygenation for severe acute respiratory distress syndrome. Intensive Care Med 2013;39:1704-13.

16. Schmidt M, Bailey M, Sheldrake J, Hodgson C, Aubron C, Rycus PT, et al. Predicting survival after extracorporeal membrane oxygenation for severe acute respiratory failure. The Respiratory Extracorporeal Membrane Oxygenation Survival Prediction (RESP) score. Am J Respir Crit Care Med 2014;189:1374-82.

17. Chiu LC, Hu HC, Hung CY, Chang CH, Tsai FC, Yang CT, et al. Dynamic driving pressure associated mortality in acute respiratory distress syndrome with extracorporeal membrane oxygenation. Ann Intensive Care 2017;7:12.

18. Bellani G, Laffey JG, Pham T, Fan E, Brochard L, Esteban A, et al. Epidemiology, patterns of care, and mortality for patients with acute respiratory distress syndrome in intensive care units in 50 countries. JAMA 2016;315:788-800.

19. Bein T, Grasso S, Moerer O, Quintel M, Guerin C, Deja M, et al. The standard of care of patients with ARDS: ventilatory settings and rescue therapies for refractory hypoxemia. Intensive Care Med 2016;42:699-711.

20. Combes A, Hajage D, Capellier G, Demoule A, Lavoue S, Guervilly C, et al. Extracorporeal membrane oxygenation for severe acute respiratory distress syndrome. N Engl J Med 2018;378:1965-75.

21. Bein T, Weber-Carstens S, Goldmann A, Muller T, Staudinger T, Brederlau J, et al. Lower tidal volume strategy ( approximately $3 \mathrm{ml} / \mathrm{kg}$ ) combined with extracorporeal $\mathrm{CO}_{2}$ removal versus 'conventional' protective ventilation $(6 \mathrm{ml} / \mathrm{kg})$ in severe ARDS: the prospective randomized Xtravent-study. Intensive Care Med 2013;39:847-56.

22. Serpa Neto A, Schmidt M, Azevedo LC, Bein T, Brochard L, Beutel G, et al. Associations between ventilator settings during extracorporeal membrane oxygenation for refractory hypoxemia and outcome in patients with acute respiratory distress syndrome: a pooled individual patient data analysis: 
mechanical ventilation during ECMO. Intensive Care Med 2016;42:1672-84.

23. Schmidt GA. Cardiopulmonary interactions in acute lung injury. Curr Opin Crit Care 2013;19:51-6.

24. MacLaren G, Combes A, Bartlett RH. Contemporary extracorporeal membrane oxygenation for adult respiratory failure: life support in the new era. Intensive Care Med 2012;38:21020.

25. Rehder KJ, Turner DA, Hartwig MG, Williford WL, Bonadonna D, Walczak RJ Jr, et al. Active rehabilitation during extracorporeal membrane oxygenation as a bridge to lung transplantation. Respir Care 2013;58:1291-8.

26. Hodgson CL, Fan E. A step up for extracorporeal membrane oxygenation: active rehabilitation. Respir Care 2013;58:1388-
90.

27. Herridge MS, Cheung AM, Tansey CM, Matte-Martyn A, DiazGranados N, Al-Saidi F, et al. One-year outcomes in survivors of the acute respiratory distress syndrome. N Engl J Med 2003;348:683-93.

28. Schmidt M, Stewart C, Bailey M, Nieszkowska A, Kelly J, Murphy L, et al. Mechanical ventilation management during extracorporeal membrane oxygenation for acute respiratory distress syndrome: a retrospective international multicenter study. Crit Care Med 2015;43:654-64.

29. Balzer F, Menk M, Ziegler J, Pille C, Wernecke KD, Spies C, et al. Predictors of survival in critically ill patients with acute respiratory distress syndrome (ARDS): an observational study. BMC Anesthesiol 2016;16:108. 
Supplementary Table S1. Changes in ventilator settings between the extended group and the conventional group during the 24-hour study period

\begin{tabular}{|c|c|c|c|}
\hline Variable & Extended group $(n=14)$ & Conventional group $(n=48)$ & p-value \\
\hline \multicolumn{4}{|l|}{ Pre-ECMO } \\
\hline Positive end-expiratory pressure, $\mathrm{cm} \mathrm{H}_{2} \mathrm{O}$ & $10(10-12)$ & $10(8-12)$ & 0.60 \\
\hline Peak inspiratory pressure, $\mathrm{cm} \mathrm{H}_{2} \mathrm{O}$ & $28(27-30)$ & $28(23-30)$ & 0.67 \\
\hline Dynamic driving pressure, $\mathrm{cm} \mathrm{H}_{2} \mathrm{O}$ & $17(15-20)$ & $16(14-20)$ & 0.58 \\
\hline Tidal volume, mL & $436(350-512)$ & $390(300-600)$ & 0.83 \\
\hline Respiratory rate, breaths/min & $23(20-28)$ & $22(16-27)$ & 0.37 \\
\hline $\mathrm{FiO}_{2}$ & $0.8(0.7-1.0)$ & $1.0(1.0-1.0)$ & $<0.001$ \\
\hline \multicolumn{4}{|l|}{4 Hours } \\
\hline Positive end-expiratory pressure, $\mathrm{cm} \mathrm{H}_{2} \mathrm{O}$ & $10(8-10)$ & $10(8-10)$ & 0.93 \\
\hline Peak inspiratory pressure, $\mathrm{cm} \mathrm{H}_{2} \mathrm{O}$ & $20(19-24)$ & $20(20-26)$ & 0.46 \\
\hline Dynamic driving pressure, $\mathrm{cm} \mathrm{H}_{2} \mathrm{O}$ & $11(10-15)$ & $12(10-15)$ & 0.58 \\
\hline Tidal volume, mL & $256(225-421)$ & $258(170-400)$ & 0.55 \\
\hline Respiratory rate, breaths/min & $16(12-20)$ & $14(11-19)$ & 0.24 \\
\hline $\mathrm{FiO}_{2}$ & $0.5(0.4-0.6)$ & $0.5(0.4-0.6)$ & 0.81 \\
\hline \multicolumn{4}{|l|}{24 Hours } \\
\hline Positive end-expiratory pressure, $\mathrm{cm} \mathrm{H}_{2} \mathrm{O}$ & $8(6-10)$ & $10(8-10)$ & 0.051 \\
\hline Peak inspiratory pressure, $\mathrm{cm} \mathrm{H}_{2} \mathrm{O}$ & $20(18-20)$ & $22(20-24)$ & 0.006 \\
\hline Dynamic driving pressure, $\mathrm{cm} \mathrm{H}_{2} \mathrm{O}$ & $10(10-12)$ & $12(10-15)$ & 0.13 \\
\hline Tidal volume, mL & $325(270-458)$ & $264(120-380)$ & 0.21 \\
\hline Respiratory rate, breaths/min & $12(12-19)$ & $14(10-20)$ & 0.92 \\
\hline $\mathrm{FiO}_{2}$ & $0.5(0.4-0.5)$ & $0.4(0.4-0.6)$ & 0.66 \\
\hline
\end{tabular}

Values are presented as median (interquartile range).

ECMO: extracorporeal membrane oxygenation; $\mathrm{FiO}_{2}$ : fraction of inspired oxygen. 